GLOBAL JOURNAL OF SOCIAL SCIENCES VOL 17, 2018: 69-76

COPYRIGHT@ BACHUDO SCIENCE CO. LTD PRINTED IN NIGERIA. ISSN 1596-6216 www.globaljournalseries.com; Info@globaljournalseries.com

\title{
THE POTENCY OF FEASIBILITY ANALYSIS ON BUSINESS SURVIVAL IN CROSS RIVER STATE SOUTHERN SENATORIAL DISTRICT, NIGERIA
}

\section{EMMANUEL EKPENYONG OKON AND MORGAN OBONG MORGAN}

(Received 7 June 2018; Revision Accepted 6 July 2018)

\begin{abstract}
This study seeks to evaluate the relevance of feasibility analysis on business survival in Cross River State Southern Senatorial district. The survey research design was adopted for this study. A population of 82 entrepreneur/owners of sachet water manufacturing companies spread across the seven local government areas of Cross River State Southern Senatorial district was used. The variables used for this study were economic analysis, staff/ personnel as well as demand and market analysis. The study found that economic analysis of feasibility enhances business survival and is statistically significant. Also, Staff/ personnel analysis of feasibility enhances business survival and is statistically significant. And as well, market and demand analysis improves business survival and is statistically significant. It was recommended that business entrepreneurs in Cross River State Southern Senatorial district should effectively carry out an economic analysis of feasibility to maximize the available resources within its disposal, hence avoiding liquidation and as well proper workforce planning should be taken into account before the take-off of any business operation for appropriate manpower hiring.
\end{abstract}

KEYWORDS: Feasibility Analysis; Business Survival; Economic Analysis; Staff/Personnel Analysis; Market and Demand Analysis

\section{INTRODUCTION}

For the success and survival of any business organization in a market-oriented economy, the key agenda lies in the responsibility of a prospective entrepreneur to carry out a proper feasibility analysis prior to the commencement of the business operations. Feasibility analysis more than any other factor is responsible for firm's growth, stagnation and decline. It is the act of evaluating the environment with the view of tracing the existing or emerging opportunities and threats and as well, the viability of the intended business with the aim of convincing the investor that the perceived project is possible or not (Ndebbio, 2007). A feasibility study is primarily concerned with a specific business type in a particular environment and location.
In Nigeria today, economic activities are being impaired by government policies and other external exigencies. Amidst these threats, business operators/entrepreneurs are lukewarm in their examination of possible opportunities and threats both in the interim and future. They hardly provide adequate justification for engaging in businesses. Businesses are also incapacitated in managerial prowess and lack avenue for sources of funds. A structural means of financial development and probability of return on investment is also lacking amongst SMEs in Cross River State which has persistently put them on a crossroad of demise.

However, a feasibility study is essential in detailing the nature of the business, environmental opportunities and threats, the justification for engaging in the business, the structure and managerial capability intended for

Emmanuel Ekpenyong Okon, Department of Business Management, University of Calabar, Nigeria. Morgan Obong Morgan, Department of Business Management, University of Calabar, Nigeria. 
the business and financial structure in relation to sourcing and appropriation. It also includes evaluating the probability of achieving a return on investment over a specific period of time and therefore an analysis to advice for a go or no-go decision to invest (Edema, 2017). Hence, for business to survive and remain sustainable, the feasibility analysis must be holistic, encompassing all the contents of a good feasibility report. This is predicated on the fact that a good feasibility analysis will help to expose both the survival and failure strategies available to an entrepreneur (Akinsanga, Oluwafemi, Alidu \& Wale, 2015).

This study, therefore, focuses on feasibility analysis and business survival with specific reference to sachet water manufacturing company in Cross River Southern Senatorial district. The study is delimited to economic analysis, staff/ personnel and demand/market analysis; this is because these sets of variables if not effectively evaluated could mare business operations.

\section{STATEMENT OF THE PROBLEM}

Cross River State has been abjured as a fertile ground for economic development as well as the existence/availability of measures for businesses to thrives such as the free trade zone and tax relief for infant businesses. However, this laudable and endearing features does not in itself avert the possible risk inherent in the business environment. Several businesses/entrepreneur despite their risk-taking potential have gone into businesses without taking a holistic evaluation of all possible organisational interaction (internal and external inclusive) as well as their potentials in handling exposures that might follow. The resultant effect of which has led to the winding-up of several businesses which barely survives within six months to one year of their operations. It has been observed that a large number of SMEs in the Southern Senatorial District of Cross River State have winded up due to their inability to withstand socio-economic exposures. It is against this backdrop that the study examines the potency of a feasibility study on business survival.

\section{OBJECTIVES OF THE STUDY}

The broad objective of this study is to examine the potency of feasibility analysis on business survival in Cross River State Southern Senatorial district. The specific objectives are as follows:

1. To determine the relevance of economic analysis on business survival

2. To examine the extent to which staff/personnel analysis enhances business survival

3. To ascertain the extent to which market and demand analysis enhances business survival

\section{RESEARCH HYPOTHESES}

The hypotheses are as follows:

$\mathbf{H}_{01}$ : Economic analysis does not significantly enhance business survival

$\mathbf{H}_{02}$ : Staff/Personnel analysis does not significantly enhance business survival

$\mathbf{H}_{03}$ : $\quad$ Market and demand analysis does not significantly enhance business survival

\section{LITERATURE REVIEW}

\section{FEASIBILITY ANALYSIS AND BUSINESS SURVIVAL}

In view of the many advantages derived from successful business enterprises, the federal government has over the years, been playing significant role towards propagating business enterprises. Worthy of note are actions for bringing about a strong business survival and sustainable growth which include: adequate institutional support; ensuring quick access to loans at reduced interest rates; establishment of industrial banks; ensuring adequate training and research and putting in place efficient monetary and fiscal policies, which are all incorporated in the feasibility report (Akinsanya et al, 2015).

Scholars of entrepreneurship are of the opinion that feasibility analysis would allow enterprises to reach their full potentials, as well as experience growth and survival. Although it must be noted that feasibility analysis as a barometer for measuring enterprise success or survival has rather been assessed than discussed. The survival of business enterprise in Cross River State depends on the potency of adequate feasibility analysis of proposed projects. The challenge experienced by small and medium enterprises in the state can be eliminated if a proper feasibility study had been carried out at the initial stage of establishing a firm. Feasibility analysis spreads across different stages in the 
operations of a firm which include organization and management, marketing, technical, financial and socio-economic stages.

Furthermore, feasibility analysis is an embodiment of the financial projections and has to do with proper estimates of the profit and the required cash for the smooth running of a firm's operations (Muro, 1983). Also, Olagunju (2004) affirmed that a proper feasibility study takes into cognizant the following: executive summary, demand and market study, technical and financial or cash flow study. The feasibility concept also anchors on the benefit and cost of the said project to the social and economic life of the citizenry. This also has to do with the negative externalities resulting from the project to the host community in terms of environmental pollution, if it is an industrial outfit (Dionco-Adetayo, 2004).

\section{ECONOMIC ANALYSIS}

This has to be done. Efforts should be made to justify what economic advantage will be achieved by establishing the business/ project. In particular, it has to show how the project will improve employment prospects and reduce social problems in the community, local government, state and Nigeria at large (Ndebbio, 2007). An effective analysis of the economy ensures that a business is being started on a positive footing because it will help in resource maximization. For example, if a proper economic analysis is carried out prior to the execution of a business plan, it will be realized that more time and resources would be expended only on the most important factors that has the capacity to make or mar the business. Other possible feasibility variables under this context should include an examination on government fiscal policy which involves the use of government's budget to enhance the level of economic activities (Koontz, O'Donnell \& Weihrich, 1983). Also, social cost which has to do with external cost such as pollution that split off. That is the negative externalities, without compensation. These costs must be included in a good feasibility analysis in order to enhance business survival. Furthermore, currency exchange which is the rate the domestic currency, naira is exchanged for other currencies in international transactions which impact on the survival of business in the state. Similarly, inflationary rate where the average prices of commodities are going up without a corresponding increase in the level of output. This is experienced through inefficient monetary framework which affects the conduct of business in the state (Koontz, O'Donnell \& Weihrich, 1983).

\section{STAFF / PERSONNEL ANALYSIS:}

A feasibility analysis should be able to ascertain the correct size of skilled and unskilled staff of the enterprise. If the proposed business or project is for road construction, more unskilled staff should be hired than skilled knowing that during the raining season, smaller proportion of the unskilled would be kept while larger proportion would be temporally laid off. Staff recruitment and training should not be based on biases, favoritism and as such other questionable indices, but must be based on merit (Ndebbio, 2007). Also, relevant questions such as what will be the organisations future human resource demand, what will be the organisations recruitment design process (communication, qualification) and selection technique that will be adopted (application form, biographical data, reference check, selection interview, ability test physical and physiological testing).

\section{MARKET AND DEMAND ANALYSIS}

This has to do with both the measurement and forecasting of demand for goods and services, which forms an important aspect of feasibility analysis. The demand for goods and services of a project (call it project demand) differs from the total market demand, in that the former is a subset of the latter. Project demand is indeed the project share of total market demand. The analysis of a project demand is important since it forms the basis of sales forecasts, cash flow forecast and other things. Any reliable demand and market analysis should not ignore key factors affecting consumer goods demand. These factors include price (a very critical factor), income, population, advertising expenditure and prices of other goods (Ndebbio, 2007).

\section{REVIEW OF EMPIRICAL LITERATURE}

Information on feasibility studies and business survival have been delved into by extant literatures. Some of the ideas posited are as contained in the work of Oke, Oluwafemi, Kareem \& Wale (2015) who examined the application of feasibility study in the establishment of small and medium scale 
enterprise in southwestern Nigeria using the multi-stage sampling technique. The study population consisted of one hundred and ninetyfive respondents. The questionnaire was applied in the field research. The study found that those who adopted feasibility study used it in accessing loans from financial institutions while some others used it in ascertaining the viability of the said or proposed business. The study recommended that when investors or entrepreneurs are actively involved in preparing their feasibility, it evades the problems during implementation.

Audu (2014) examine the impact of feasibility study in enhancing growth and development of business organizations in Nigeria using the survey design with a population of sixty respondents. It was found that greater proportion of respondents indicated that feasibility had a positive impact in stimulating growth and development of business organizations. The study recommended that management consultants should be employed in crafting out the feasibility plan, since they are knowledgeable in that area. Also another study by Abbrey, Bagah \& Wulifan (2015) on the relevance of business planning document for small and medium scale enterprise in Northern Ghana. The survey design was adopted and the research found that just very few small scale business managers carry out intensive planning before the commencement of any business operations. It was also recommended that business operators should be well guided by management experts in the business planning process. Another study was carried out by Praag (2003) on business survival and success of young small business owners. The survey design was used and twelve thousand respondents were used as the study population. It was found that good feasibility report enhances business survival. In similar vein, a study conducted by Akpa-udo (2016) on PEST analysis of businesses on the growth of SMEs in Northern senatorial district of Cross River State of Nigeria reveals that appropriate evaluation of political and economic environment of business operation gives an entrepreneur firsthand information on how to romance with government policies and manage economic exigencies.

\section{SUMMARY OF LITERATURE REVIEW}

Adequate feasibility analysis is required for the smooth running of a firm's operations (Muro, 1983). It revolves on the futuristic perception of business survival which is inclusive of demand and market study, technical and financial or cash flow study. From array of extant literatures; supports have been accorded to the relevance of feasibility study which includes the fact that investors, who are actively involved in the preparation of feasibility studies of their businesses, avert problems during operation. Management who engages in feasibility plan and are knowledgeable in that area are bound to survive during operational turbulence. A study carried out in northern Cross River also reveals that feasibility study through PEST analysis gives entrepreneurs a first-hand information on how to romance with government policies and manage economic exigencies. By extension, feasibility study is no doubt relevant to the survival of businesses both within and outside southern senatorial district of Cross River State.

\section{METHODOLOGY}

The survey research design was applied in this study to $x$-ray the content of the variables considered to be included in any good feasibility report and this relied on primary data. The analysis on the dependency of feasibility study on business survival in Cross River State was presented using economic, staff/personnel as well as market/demand analysis. The essence of this analysis in the context of this study is to systematically ascertain the dependency of business survival on a good feasibility report. The population of the study constituted entrepreneurs/ owners of sachet water manufacturing companies in Cross River State Southern Senatorial district. Sachet water producing companies in the seven local government areas that comprise Southern Senatorial District of Cross River State is estimated at 82 . Thus a census of the entire population was used for the study.

The multiple regression analysis was adopted to test all the hypotheses formulated for the study. This analysis is used when considering the relevance of independent variables on the 
dependent. Regression is more of a predictive statistical tool in nature and the variables are continuous. It was therefore considered to be adequate in testing the hypothesis formulated for this study. However the multiple regression model was used, the specified model is of the form:

$Y=\beta_{0}+\beta_{1} X_{1}+\beta_{2} X_{2}+\beta_{3} X_{3}+\varepsilon$

Where $\beta_{1}, \beta_{2}-\cdots-\beta_{3}$ are regression coefficients

BUSUV $=\mathrm{f}\left(F E A S_{i}\right)$

Where FEAS symbolize feasibility analysis which is evaluated by economic analysis (ECO.A), staff/ personnel analysis (STP.A) and market/demand analysis (MKTD.A); and BUSUV symbolize business survival which is measured in terms of profitability $(P)$, sales volume $(\mathrm{SV})$ and return on equity (ROE).

Therefore, in enlarged form we have:

BUSUV $=f(E C O . A$, STP. A, MKTD. A, u $)$

In linear form we obtain,

BUSUV $=\beta_{0}+\beta_{1}$ ECO.A $+\beta_{2}$ STP.A $+\beta_{3}$ MKTD. A $\left.+\varepsilon\right)$

Where

BUSUV $=(P, S V \&$ ROE $)$

ECO. $A_{1}=$ Economic analysis

ST $/$ P. $A_{2}=$ Staff $/$ Personnel analysis

MKTD. $A_{3}=$ Market and demand analysis

$\varepsilon \quad=\quad$ Error term. $\beta_{0}=$ Regression parameter estimates

$\alpha=$ Alpha level

Where:

$\mathbf{H}_{01}$ : Economic analysis does not significantly enhance business survival

$\operatorname{BUSUV}(\mathrm{P})=f(\mathrm{ECO} . \mathrm{A})$

$P=\alpha=\beta_{0}+($ ECO.A $)+\varepsilon$

$\mathbf{H}_{02}$ : Staff/Personnel analysis does not significantly enhance business survival

$\operatorname{BUSUV}(\mathrm{SV})=f($ STP. A $)$

$S V=\alpha=\beta_{0}+(E C O . A)+\varepsilon$

$\mathbf{H}_{03:} \quad$ Market and demand analysis does not significantly enhance business survival

BUSUV $($ ROE $)=f($ MKTD. A $)$

$\mathrm{ST}=\alpha=\beta_{0}+$ (MKTD. A) $\varepsilon$

The data was analyzed using multiple regression analysis. This is due to the fact that the study sought to establish the potency of feasibility analysis on business survival in Cross River State Southern Senatorial district. In view of this, the gathered data was analyzed using multiple regression analysis. 
Presentation and interpretation of regression result

Table 1: Presentation of multiple regression result Dependent variable: BUSUV ( $P, S V \&$ ROE)

\begin{tabular}{|c|c|c|c|c|c|c|}
\hline \multirow[t]{2}{*}{ S/I } & \multirow[b]{2}{*}{ Variables } & \multicolumn{2}{|c|}{ Unstandardized Coefficients } & \multirow{2}{*}{$\begin{array}{l}\text { Standardized } \\
\text { Coefficients } \\
\text { Beta }\end{array}$} & \multirow[t]{2}{*}{ t-cal } & \multirow[t]{2}{*}{ Sig. } \\
\hline & & B & Std. Error & & & \\
\hline \multirow{4}{*}{$\begin{array}{l}1 \\
2 \\
3\end{array}$} & (Constant) & 5.357 & .451 & & 6.345 & $.001^{*}$ \\
\hline & ECO.A & .445 & .028 & .552 & 4.264 & $.000^{* *}$ \\
\hline & ST/P.A & 1.028 & .045 & .936 & 4.511 & $.000^{* *}$ \\
\hline & MKTD.A & .255 & .069 & .521 & 3.326 & $.001^{*}$ \\
\hline
\end{tabular}

$$
\begin{gathered}
\mathrm{R}=.713 \\
\mathrm{R}^{2=} .635 \\
\mathrm{R}^{2} \mathrm{Adj} .=.632 \\
\text { F-ratio. }=29.452 \\
\text { Significant @P }<.05 \\
\text { Source: Field work }(2018)
\end{gathered}
$$

\begin{abstract}
ANALYSIS AND DISCUSSION OF FINDINGS
The summary of multiple regression result reveals a significant degree of relationship between the regressand business survival and the regressors-economic analysis, staff/personnel analysis as well as market and demand analysis. This is so because the Rsquared in the model 0.635 indicating 63.5 percent relationship between the regressand and the regressors. The remaining 36.5 percent variations in the model are explained by other factors not included in the model. The adjusted $\mathrm{R}^{2}$ of .632 indicated a 63.2 percent variation of the independent variables (economic analysis, staff/personnel analysis and market and demand analysis) that actually affect the dependent variable (business survival).
\end{abstract}

The estimated results indicated that economic analysis have a positive effect on business survival measure in terms of (profitability) as $(t=4.264, p=.000)$; Staff/Personnel analysis have a positive influence on businesses survival measure in terms of (sales volume) as ( $\mathrm{t}=4.511$, $p=.000$ ); and market and demand analysis have a positive impact on business survival, measured in terms of (return on equity) as $(t=3.326, p=.001)$. Furthermore, the result shows that economic analysis, Staff/Personnel analysis and market and demand analysis all have significant positive effect on business survival, measured in terms of (profitability, sales volume and return on equity).

The calculated F-ratio of 29.452 was greater than the significant values of 3.84 , at $\mathrm{P}<0.05$ significant level. Based on the result, the entire null hypothesis Ho was rejected while all the alternative $\mathrm{Hi}$ was accepted. This implies that feasibility analysis have significant positive effect on business survival in Cross River State Southern Senatorial District of Nigeria.

On the t-test of all the parameter estimates, i.e economic analysis, staff/personnel and market and demand analysis were statistically significant. From the table the estimated regression line showed a positive relationship between economic analysis and business survival. The statistical test carried out on the variable indicates that it is statistically significant at 0.05 percent level of significance. An effective economic analysis of a feasibility study will help the entrepreneur maximize the available resources within its disposal with little or no stress and thus ensures that the business is grounded on a positive footing.

The estimated result equally indicates a positive relationship between staff/personnel and business survival. The statistical test carried out on the variable indicates that it is statistically 
significant at 0.05 percent level of significance. Proper feasibility analysis will help an investor ascertain the correct size of skilled and unskilled personnel to hire. Furthermore, the estimated result equally shows a positive relationship between market and demand analysis on business survival, and the statistical test conducted on the variable at 0.05 percent level of significance showed that the variable is statistically significant. Proper feasibility analysis will enable the entrepreneur collect and analyze past and current data on demand for a product.

The R-squared value of 0.635 showed that about 63.5 percent of the total variations in the dependent variable have been explained by the independent variables. Hence, the model has a good fit. The result of overall significance of the model using F-statistic shows that the model is statistically significant at 0.05 percent level of significance. From the above analysis, the following findings were made:

1 Economic analysis of feasibility enhances business survival and is statistically significant.

2 Staff/ personnel analysis of feasibility enhances business survival and is statistically significant.

3 Market and demand analysis enhances business survival and is statistically significant.

\section{CONCLUSION}

This study which is on feasibility analysis and business survival in Cross River State Southern Senatorial district delved on those factors that must be included in a good feasibility report to enhance the survival of business in the state, most especially sachet water manufacturing company. It further concluded that business entrepreneurs who made use of a proper feasibility study to determine the viability of their businesses stand to gain maximally. Furthermore, the study concludes that not minding the challenges in implementing feasibility analysis of a business; its availability has assisted entrepreneurs in taking crucial business decisions that will not allow their businesses to go into liquidation.
RECOMMENDATIONS

From the findings the following recommendations were made:

1. Business entrepreneurs in Cross River State Southern Senatorial District should effectively carry out economic analysis of feasibility in order to maximize the available resources within its disposal, hence avoiding liquidation.

2. The structure of market demand and supply should be systematically undertaken by firms in the district. This will help provide first- hand information on products before establishing such business outfit in the area.

3. Proper manpower planning should be taken into account before the take-off of any business operations for appropriate man power hiring.

\section{REFERENCES}

Akinsanya, Oluwafemi, Alidu and Wale., 2015. Application of feasibility study in establsihment of small and medium scale enterprise in Southern Western Nigeria. European Journal of Business and Management, 7(24),31-38.

Akpa-udo, E., 2016. PEST analysis of businesses on the growth of SMEs in Northern senatorial district of Cross River State of Nigeria. International Journal of Business and Management, 2 (4), 54-60.

Audu, M. A., 2014. The impact of feasibility study in enhancing growth and development of business organization in Nigeria. Jorunal of Business and Management, 16(6), 3238.

Dionco-Adetayo, E., 2004. Determinant of small firms enterprenurial success in developing economy. Ile-Ife: Obafemi Awolowo Univerity lle-Ife.

Edema, A., 2017. Feasibility study. Unpublished Lecture Note, Department of Business Management, University of Calabar, Calabar. 
Jochebed, A., Bagah, D. A. and Wulifan, J. K.,

2015. The relevance of business planing document of small and medium scale enterprise in Tamali Metropilis, Northern Ghana, 7 (1) 34-50.

Muro, V., 1983. Preparing project feasibility studies. Quezon City: Phoenix Press.

Ndebbio, U. N., 2007. Project planing and evaluation. Calabar: University of Calabar Press.

Oke, A., Oluwafemi, A., Kareem, A. and Wale, A.,

2015. Application of feasibility study in the establishment of small medium scale enterprises in southwestern Nigeria. European Journal of Business and Management, 7(24), 31-39.
Olagunju, Y. A., 2004. Entrepreneurship small scale business enterprise development in Nigeria. Ibadan: University Press Plc Nigeria.

Prag, M. C., 2003. Business survival and success of young small business owners. London: Oxford Press. 